\title{
ANÁLISE DA DEGRADAÇÃO AMBIENTAL DECORRENTE DA FORMA DE OCUPAÇÃO DO RELEVO: UM ESTUDO DO BAIRRO JARDIM HUMBERTO SAlvador - Presidente Prudente -SP
}

Leda Correia Pedro'

\section{Marcel Bordin Galvão Dias ${ }^{2}$}

RESUMO: O objetivo desta pesquisa foi realizar uma análise preliminar da situação da degradação ambiental em uma área urbana periférica de Presidente Prudente, onde se encontra o Conjunto Habitacional Jardim Humberto Salvador e identificar os principais impactos ambientais que contribui para o estágio de degradação ambiental do bairro em análise. Para que os objetivos fossem alcançados necessitou-se dos seguintes procedimentos metodológicos, sendo estes: a) Levantamento bibliográfico; b) Aplicação de entrevistas e questionários; c) Elaboração de mapeamentos temáticos; d) Trabalho de campo. Dessa forma, foi possível verificar que o Conjunto Habitacional Jardim Humberto Salvador é marcado por um quadro de degradação ambiental vinculado a forma como os agentes de produção do espaço urbano, principalmente a Prefeitura Municipal, se apropriou e iniciou a ocupação do loteamento, a qual não considerou de forma adequada a dinâmica dos processos geomorfológicos, pedológicos, hídricos etc. Como resposta a esta intervenção vários impactos ambientais urbanos foram identificados, como diferentes formas erosivas (sulcos, ravinas e voçorocas), assoreamento, desabamento, depósitos tecnogênicos, entre outros.

Palavras-chave: Uso e ocupação. Degradação ambiental. Área urbana.

\footnotetext{
${ }^{1}$ Doutoranda, Programa de Pós-Graduação em Geografia da Universidade Estadual Paulista, campus de Presidente Prudente/SP. lecpgeo@gmail.com

${ }^{2}$ Mestrando, Programa de Pós-Graduação em Geografia da Universidade Estadual Paulista, campus de Presidente Prudente/SP.mbgdias@gmail.com
} 


\section{INTRODUÇÃO}

A cidade de Presidente Prudente, localizada no Planalto Ocidental Paulista, região oeste do estado de São Paulo, vem apresentando problemas ambientais urbanos vinculados ao mau uso da terra, em um meio físico com suscetibilidade natural à erosão, comuns na referida macrounidade geomorfológica.

Os principais problemas ambientais urbanos estão associados à devastação de áreas florestadas, assoreamentos e contaminação de cursos d'água, aceleração de processos geomorfológicos e erosão do solo, a partir da intervenção antrópica.

O "homem" ao se apropriar e ocupar um determinado compartimento geomorfológico, seja ele, topo, vertente ou fundo de vale, acaba por interferir na dinâmica natural dos processos geomorfológicos, pedológicos, hídricos etc. As alterações nestes processos resultam em impactos diversos, a exemplo daqueles ligados a degradação do solo (processos erosivos) e a formação de depósitos tecnogênicos (depósitos resultantes da ação geológica do homem, no qual são encontrados artefatos de origem antrópica em meio às camadas do solo).

Esta situação pode ser compreendida dentro de um contexto que envolve as relações existentes entre homem e natureza, especialmente no processo de produção do espaço urbano.

A maneira como os compartimentos do relevo vêm sendo apropriados e ocupados, privilegiam as relações homem-homem (relações de produção), de forma a deixar subordinada a natureza, reconhecida como um recurso. De acordo com Casseti (1991, p. 87), o processo de ocupação e transformação "dos compartimentos geomorfológicos", no "sistema de produção capitalista, que é uma relação homem-meio, encontra-se subordinada às relações homem-homem, que tem na relação de propriedade das forças produtivas a categorial principal". Se tal relação de propriedade das forças do capitalismo separa os homens em classes (proletariado e burguesia) e o espaço é "mercadoria", torna-se evidente que as diferenciações espaciais resultam do próprio poder de compra. Diante disso, enquanto se destinam as melhores condições topográficas (de relevo) àqueles que detêm o capital, sobram as áreas de risco aos desvalidos e marginalizados da elite econômica. 


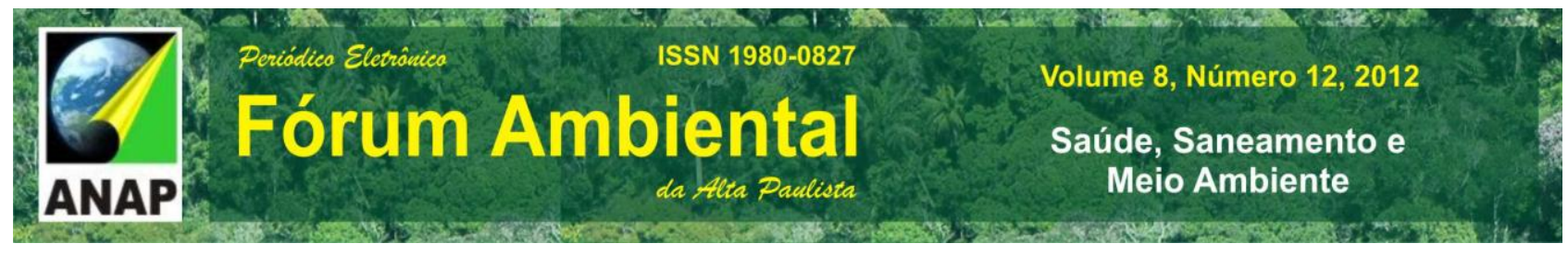

Dessa maneira, o uso e a ocupação da terra em áreas urbanas são decorrentes da forma como os agentes de produção do espaço urbano ${ }^{3}$ vêm se apropriando e ocupando estas áreas. Para se entender como estes processos (apropriação, ocupação e uso) ocorrem é de fundamental importância conhecer o histórico de apropriação e ocupação da cidade e os devidos usos da terra, que podem contribuir na identificação dos principais processos de degradação e propor alternativas para mitigar os impactos ambientais urbanos.

Diante desse quadro, a cidade de Presidente Prudente, que se encontra sobre um relevo composto por colinas amplas, teve seu primeiro núcleo urbano implantado em áreas de topo. Conforme a cidade foi se expandindo territorialmente, ocorreu a incorporação de outros compartimentos geomorfológicos, sendo estes as áreas de alta, média e baixa vertente e os fundos de vale. A lógica de apropriação e ocupação dos agentes de produção do espaço urbano acabou por influenciar a expansão territorial da cidade, sendo que o eixo leste e norte, onde se encontram formas de relevo com declives mais acentuados, não sofreram uma expansão territorial tão significativa, quando comparada ao eixo oeste da cidade, que têm relevos mais suaves e planos e, por sua vez, possuem terrenos mais valorizados.

No eixo leste e norte estão concentrados bairros que apresentam terrenos significativamente pequenos, instalados em áreas com declividades acentuadas e onde estão concentradas as áreas de exclusão social (CEMESPP $\left.{ }^{4}, 2000\right)$. De acordo com Mazzini (1997), neste eixo também estão concentradas as antigas áreas de deposição de resíduos sólidos (lixo). Todos estes fatores são decorrentes da forma como os agentes de produção do espaço urbano atuaram principalmente no fato de valorizar algumas áreas que possuem determinadas características físicas (relevo) em detrimento de outras.

Assim, as áreas com declividades mais acentuadas, os antigos depósitos de resíduos sólidos e que têm uma população enquadrada no grupo de exclusão social, apresentam um quadro de degradação ambiental, decorrente da forma de apropriação, ocupação e uso da terra.

\footnotetext{
${ }^{3}$ São os proprietários fundiários, os promotores imobiliários, o Estado e o consumidor (CORREA, 1989).

${ }^{4}$ Centro de Estudos sobre Mapeamento da Exclusão Social para Políticas Públicas.
} 


\section{OBJETIVO}

O objetivo deste trabalho foi realizar uma análise preliminar da situação de degradação ambiental em uma área urbana periférica de Presidente Prudente, onde se encontra o Conjunto Habitacional Jardim Humberto Salvador e identificar os principais impactos ambientais que contribuem para o estágio de degradação ambiental do bairro em questão.

\section{PROCEDIMENTOS METODOLÓGICOS}

A metodologia aplicada para se alcançar o objetivo proposto, envolveram procedimentos:

a) Levantamento bibliográfico, para compreender o processo histórico de apropriação e ocupação da cidade de Presidente Prudente e o bairro Jardim Humberto Salvador, bem como, identificar as principais forma de atuação dos agentes de produção do espaço urbano e sua contribuição para a valorização de determinadas formas de relevo;

b) Aplicação de questionários para elaboração de um perfil socioeconômico dos moradores da área de estudo.

c) Elaboração de cartas temáticas representativas da declividade, hipsometria e o uso e ocupação da terra. As cartas foram elaboradas com a utilização do programa Spring $^{5}$, (carta de declividade e hipsometria), por meio de fotointerpretação (geomorfológica) e a carta de uso e ocupação do solo. A elaboração gráfica da carta de uso e ocupação do solo e vegetação foi elaborada a partir de imagem do Google Earth ${ }^{6}$, utilizando o programa CoreIDRAW $\times 3^{7}$.

\footnotetext{
${ }^{5}$ SPRING- Integrating remote sensing and GIS by object-oriented data modelling Camara G, Souza R.C.M, Freitas U.M. Garrido J. Computers \& Graphics, 20: (3) 395-403, May-Jun 1996.

${ }_{7}^{6}$ Google Earth é marca registrada Google.

7 Corel Draw é marca registrada da Corel Corporation.
} 
d) Trabalho de campo para validar as informações espacializadas nas cartas e identificação das principais formas de degradação ambiental, decorrentes do uso e ocupação da terra.

\section{RESULTADOS E DISCUSSÃO}

A partir da análise do histórico de apropriação e ocupação dos compartimentos geomorfológicos da cidade de Presidente Prudente foi possível compreender a situação atual de degradação ambiental do Conjunto Habitacional Jardim Humberto Salvador (fig.01). O empreendimento foi implantado em 1995 a partir do Projeto de Loteamentos Urbanos, com o objetivo de auxiliar o acesso à moradia, pessoas que não foram atendidas no Programa de Desfavelamento. Assim, o projeto envolveu a re-locação de parte da população que residiam em áreas de favela localizadas na zona leste da cidade de Presidente Prudente (SP).

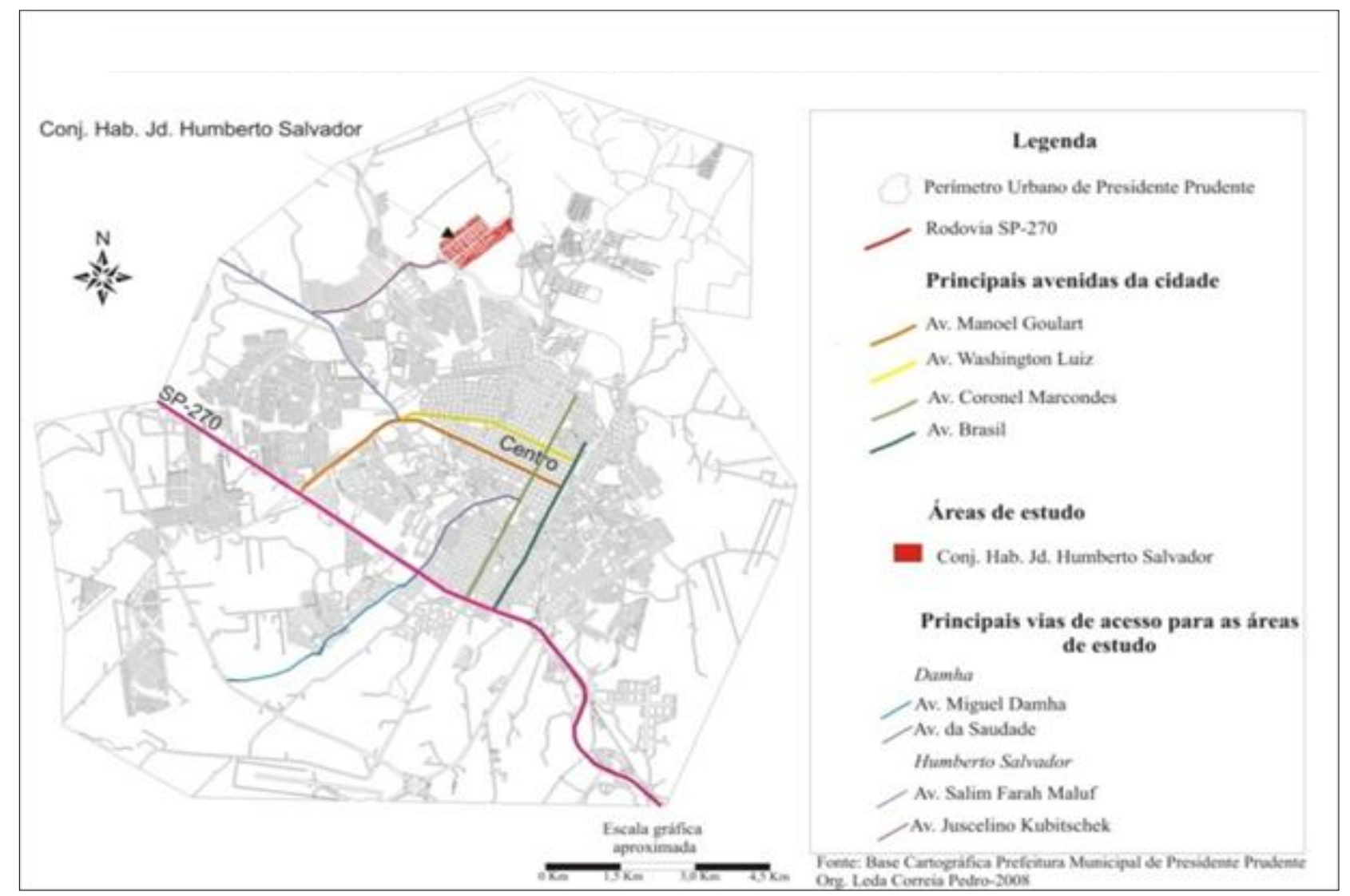

Figura 01: Mapa de localização do Conjunto Habitacional Humberto Salvador, em Presidente Prudente (SP) 
Os moradores contemplados receberam lotes para serem edificados em um período de dois anos, não podendo aliená-lo por 10 anos, conforme as condições estabelecidas e especificadas pela Prefeitura Municipal de Presidente Prudente ${ }^{8}$, agente incorporador e loteador.

Diante das condições socioeconômicas da população que ocupou esta área, muitos problemas foram detectados por meio do questionário e de conversas com os moradores. Entre eles podem ser citados: a implantação de um Conjunto Habitacional descontínuo à malha urbana, fato que dificulta o acesso dos moradores às áreas centrais, onde se localizam grande parte dos serviços buscados pela população; a falta de asfalto em algumas vias; a ausência parcial de iluminação pública em alguns locais; a necessidade de construção de creches e posto de saúde, entre outros.

O veículo de comunicação utilizado pelas famílias para a reivindicação destes e outros serviços, como telefones públicos e limpeza pública, foi o jornal local. Um agente importante que auxiliou e ainda auxilia na reivindicação de melhorias para o Conjunto Habitacional Jardim Humberto Salvador é a Associação de Moradores, que busca a solução de problemas relacionados à infraestrutura e a precariedade da oferta de serviços oferecidos à população residente.

O estudo do relevo do bairro demonstra algumas características relacionadas aos projetos de urbanização de Conjunto Habitacionais destinados à população carente. Pode-se observar na carta Geomorfológica do Conj. Habitacional (fig. 02), que a malha urbana foi sobreposta ao terreno (relevo) sem considerar as características do relevo local, assim o relevo foi adaptado ao projeto de loteamento e não o inverso. Assim, a ocupação se deu principalmente nas áreas de topo e no domínio das vertentes, incorporando áreas de nascentes e canais de escoamento ao bairro.

${ }^{8}$ Para mais informações ler Jesus (2005) e Pedro (2008). 

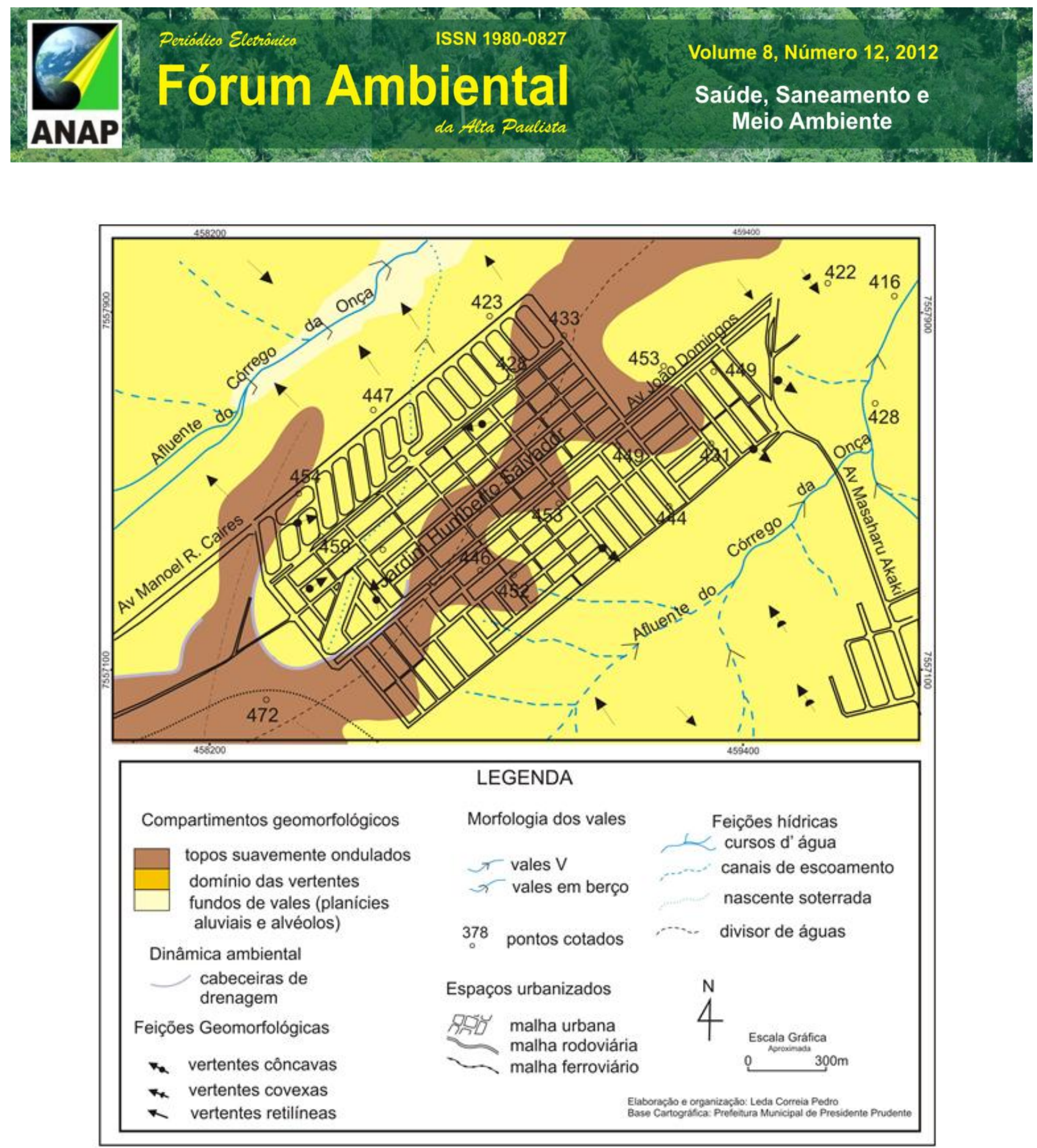

Figura 02. Carta Geomorfológica do Conjunto Habitacional Jardim Humberto Salvador

As áreas de topo apresentam morfologia suavemente ondulada com colinas médias, atingindo altitudes entre 445 e 460 metros, conforme a carta hipsométrica (fig.03). Também é possível encontrar cabeceiras de drenagem em anfiteatro, descaracterizadas pela divisão em lotes e subsequente construção. 

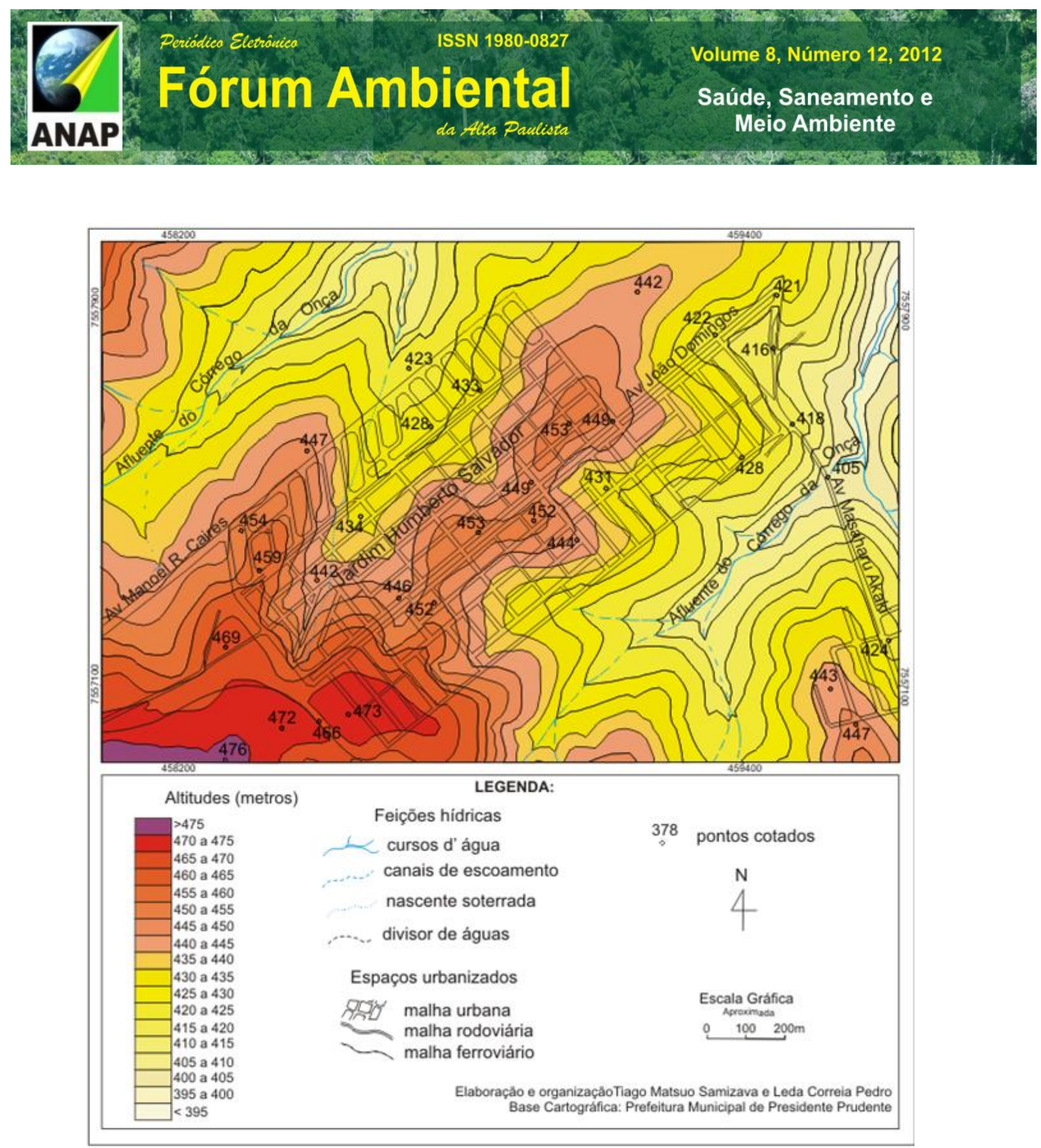

Figura 03. Carta Hipsométrica do Conjunto Habitacional Jardim Humberto Salvador

As declividades (fig.04) identificadas nas vertentes é um importante fator a ser considerado para a estruturação de um plano de ocupação de um local. De acordo com a declividade encontrada, incluindo outros fatores a serem considerados, são classificadas como áreas não parceláveis para a ocupação urbana. No Humberto Salvador as morfologias das vertentes são convexo-côncavo e retilíneas, sendo que em alguns casos encontram-se seguimentos mistos. As declividades, conforme carta elaborada por Pedro (2008) encontra-se na maioria até $15 \%$, sendo considerados apropriados a ocupação e 


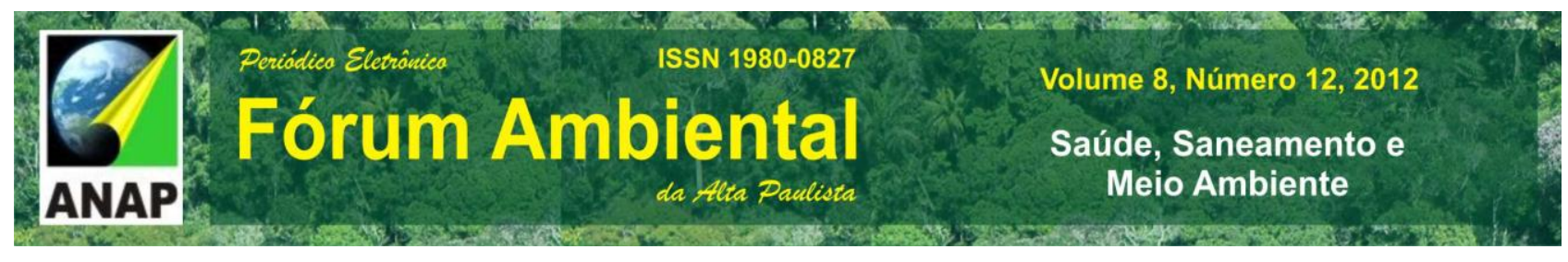

uso urbano. No entanto, há algumas exceções nas quais a declividade chega a alcançar $30 \%$ de inclinação, onde há riscos de desabamento de estruturas de contenção.

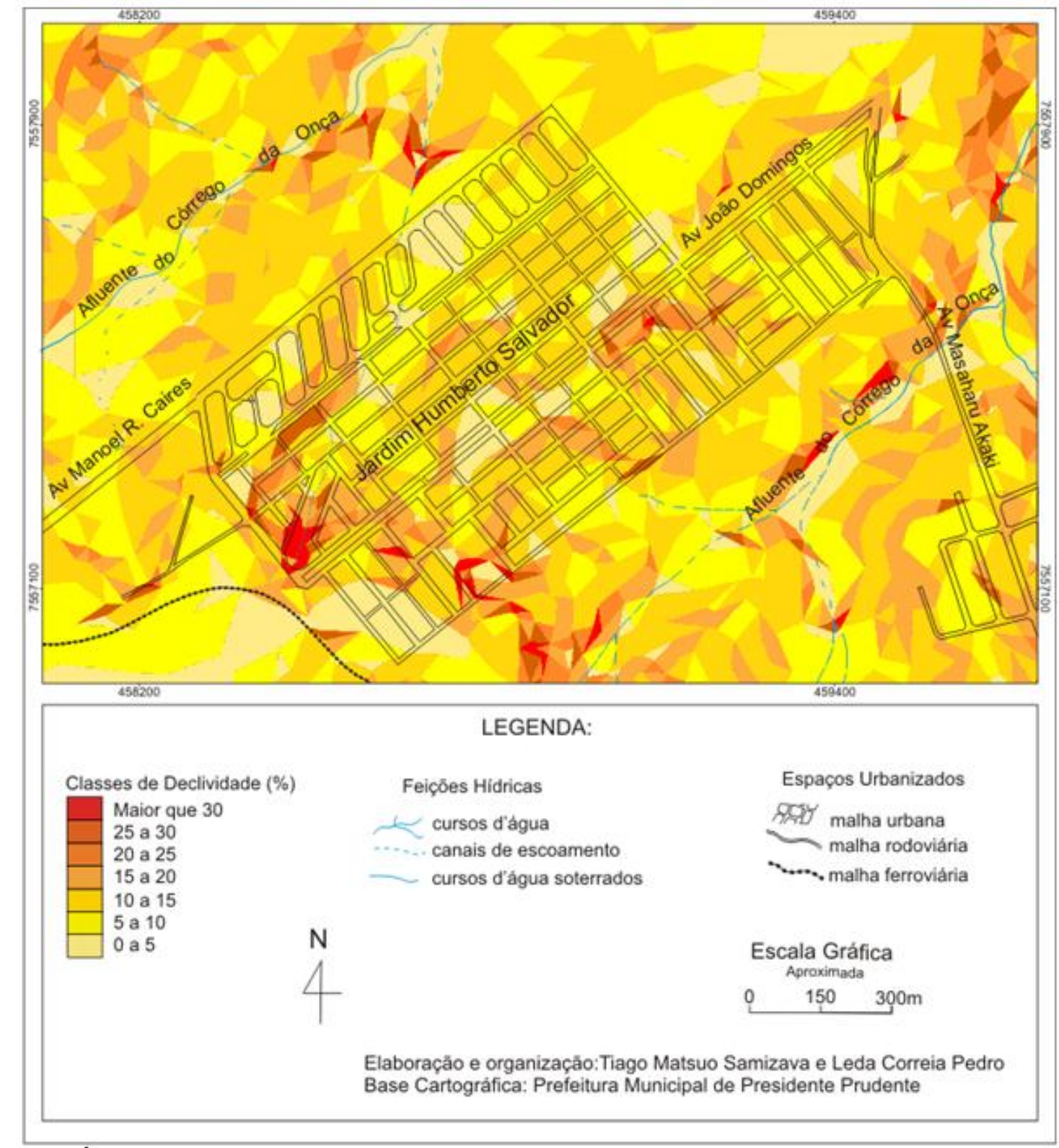

Figura 04. Carta de Declividades do Conjunto Habitacional Humberto Salvador

Quanto às características físicas do bairro e das proximidades do mesmo, percebese que ocorreu, em consequência da concretização da ocupação urbana, severas alterações no quadro ambiental, como o soterramento de nascentes e redução do volume de água dos afluentes do córrego da Onça. Destaca-se também a formação dos 
depósitos tecnogênicos nas proximidades dos afluentes do córrego da Onça, pois grande parte dos artefatos humanos são depositados ou carreados com o escoamento das águas superficiais para partes mais baixas do relevo, como nas planícies aluviais e, neste caso específico, no interior de feições erosivas. Os processos erosivos encontrados nas formas de sulcos, ravinas e voçorocas também estão presentes no bairro, principalmente em lotes sem edificação e com solo exposto.

Devido à adaptação do relevo ao projeto de loteamento, alguns cortes nas vertentes foram esculpidos. Dessa forma, fez necessária a construção de muros de arrimo, para atribuir-Ihes estabilidade. Em taludes com altura de até 1,5 metros, o muro de arrimo pode ser construído com alvenaria. Já naqueles com altura superior, necessita-se da construção de muros com concreto armado. Contudo, esta é uma medida que despende um custo relativamente alto, principalmente ao considerar a carência da população local. No período chuvoso foram identificados vários taludes que desabaram e algumas residências interditadas, pois corriam risco de desabamento.

Em relação aos fundos de vales da área estudada, as morfologias descritas no trabalho de Pedro (2008) são em V e em berço. No caso dos vales com fundo chato, as declividades variam até $15 \%$, podendo configurar-se em áreas de planícies. Os vales em $V$, que também são encontrados na área, apresentam declividades entre $20 \%$ e 30\%, superando estas medidas em alguns pontos.

Apesar da necessidade de se estudar os elementos relacionados ao relevo do local, com destaque para os aspectos morfológicos e morfométricos, é indispensável a análise dos impactos decorrentes da ação antrópica.

Um aspecto importante da caracterização da área é o grande adensamento de construções. Estas foram dispostas em lotes, através de malha urbana com forma retangular, que ocupam os topos e as vertentes, não considerando o relevo original, e sim o alterando através de ações como cortes para a divisão das ruas e dos lotes.

A impermeabilização ocorreu de maneira ampla sobre estes compartimentos do relevo. Durante o período das chuvas, a água pouco infiltra e escoa em grande quantidade, acumulando em algumas áreas do loteamento, conforme observado por Pedro (2008). 


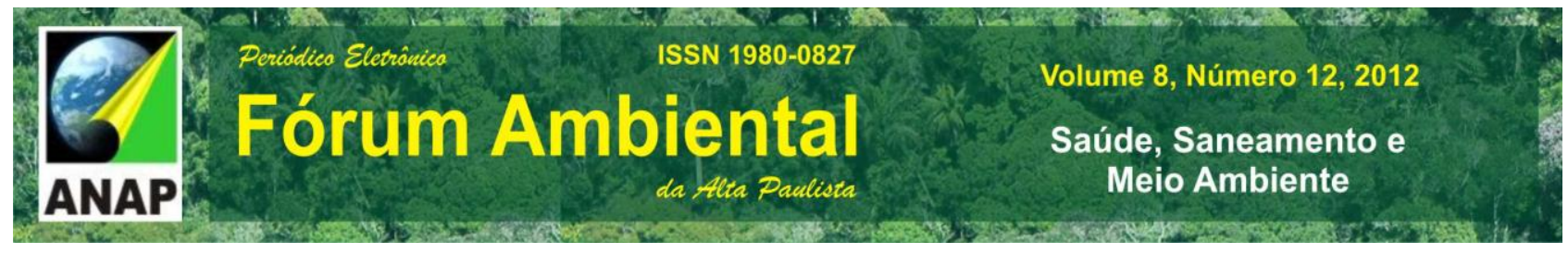

Este fato está relacionado com o desenvolvimento de processos erosivos, principalmente nas vertentes e nos fundos de vales. Os processos erosivos ocorrem naturalmente num determinado ambiente, podendo ser acelerado na presença de determinadas características do clima, do relevo, do solo e outras. Porém, a ação humana no ambiente, como o desmatamento e a impermeabilização, aceleram estes processos que demorariam mais para ocorrer caso não houvesse esta interferência.

Outra questão é o acúmulo de sedimentos oriundos do escoamento superficial da água. Devido à impermeabilização e o conseqüente aumento do volume de água que escoa, grande parte dos sedimentos oriundos do topo são carreados para as partes mais baixas do terreno, causando diversos problemas, como o assoreamento dos cursos d'água. A ação humana é responsável, também, pela formação dos depósitos tecnogênicos, que puderam ser observados através dos trabalhos de campo.

A implantação do bairro modificou diversas características do relevo e outras dinâmicas ligadas a ele, como a dinâmica hídrica e a cobertura vegetal, conforme pode ser observado na carta de uso e ocupação do solo e vegetação (fig. 05).

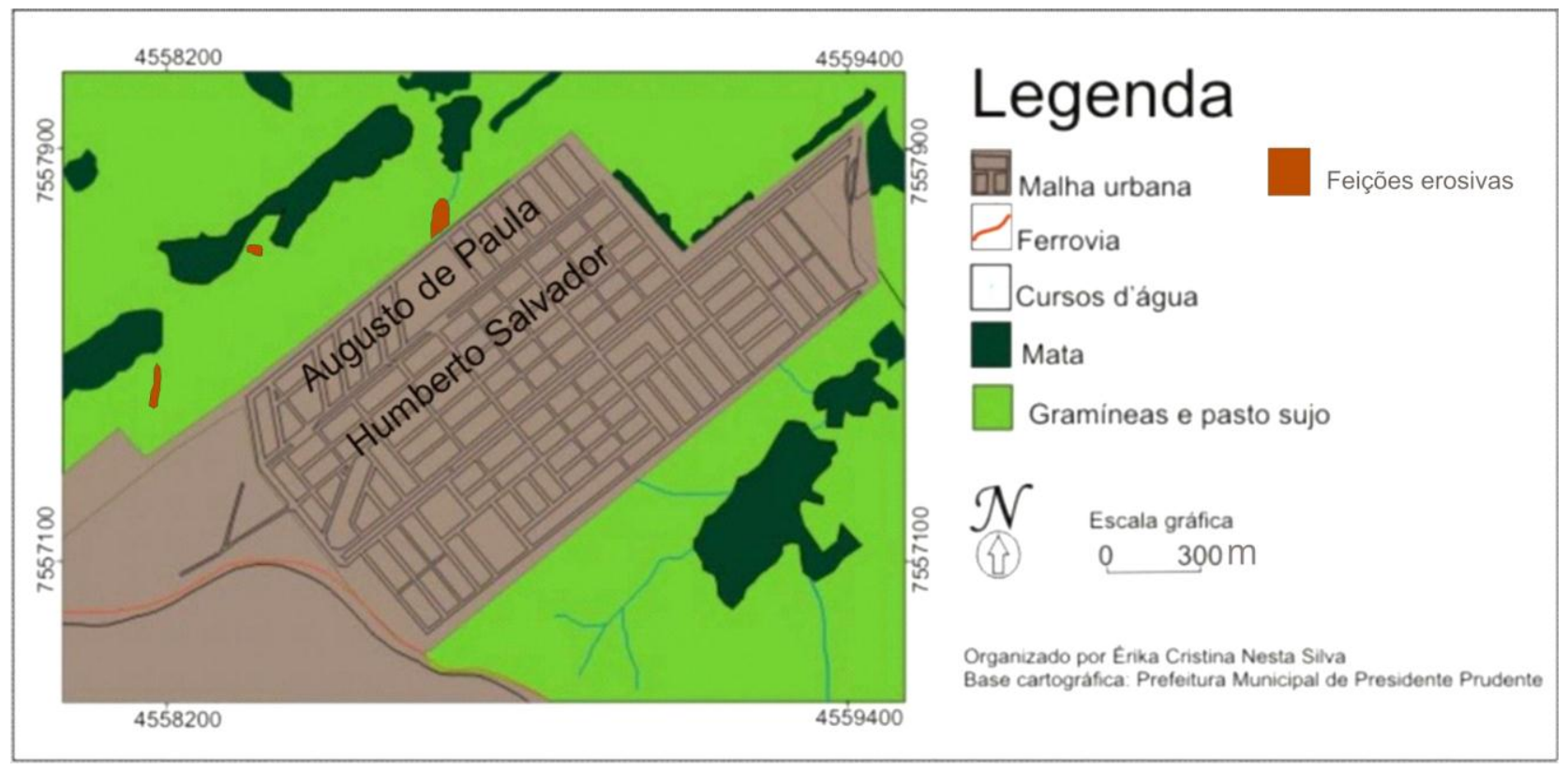

Figura 05. Carta de uso e ocupação e vegetação do conjunto Habitacional Humberto Salvador. Fonte: Silva (2009)

Assim, o estudo do conjunto de características naturais da área e da forma de ocupação da sociedade mostra-se relevante ao possibilitar a compreensão do modo como 
a sociedade altera as diversas dinâmicas da natureza para satisfazer suas necessidades, como a de moradia.

\section{CONCLUSÕES}

A partir da pesquisa, foi possível verificar que o Conjunto Habitacional Jardim Humberto Salvador é marcado por um quadro de degradação ambiental. Este quadro se encontra vinculado à forma como os agentes de produção do espaço urbano, principalmente a Prefeitura Municipal, se apropriou e iniciou a ocupação do loteamento, a qual não considerou de forma adequada a dinâmica dos processos geomorfológicos, pedológicos, hídricos. Como resposta a esta intervenção vários impactos ambientais urbanos foram identificados, como diferentes formas erosivas (sulcos, ravinas e voçorocas), assoreamento dos corpos hídricos, desabamentos de taludes, bem como a gênese dos depósitos tecnogênicos, registros da ação humana na paisagem.

Assim, este estudo contribuiu principalmente na compreensão dos efeitos e respostas da dinâmica dos processos naturais quando há intervenção antrópica. A partir dos mapeamentos temáticos e outras técnicas é possível planejar de forma adequada o uso da terra considerando a dinâmica da natureza nos ambientes urbanos, no intuito de que os impactos ambientais urbanos sejam evitados e o quadro de degradação seja minimizado ou evitado.

\section{REFERÊNCIAS BIBLIOGRÁFICAS}

CASSETI, V. Ambiente e apropriação do relevo. São Paulo: Contexto, 1991.

CORREA, R. L. O espaço urbano. São Paulo: Ática, 1989.

JESUS, P. M. Produção do espaço urbano no Jardim Humberto Salvador, Presidente Prudente-SP: Afastamento, Exclusão ou Segregação Socioespacial? 2005. Monografia (Bacharelado em Geografia). Universidade Estadual Paulista, Faculdade de Ciências e Tecnologia. Presidente Prudente: [s.n.], 2005. 
MAZZINI, E. J. De lixo em lixo em Presidente Prudente (SP): novas áreas, velhos problemas. 1997. Monografia (Bacharelado em Geografia). Universidade Estadual Paulista, Faculdade de Ciências e Tecnologia. Presidente Prudente: [s.n.], 1997.

OLIVEIRA, A. M. S. et al. Tecnógeno: registro da ação geológica do homem. In: SOUZA, C. R. G. [et al] (ed.) Quaternário do Brasil. Ribeirão Preto: Holos, 2005.

PEDRO, L. C. Ambiente e apropriação dos compartimentos geomorfológicos do Conjunto Habitacional Jardim Humberto Salvador e Condomínio Fechado Damha. Dissertação (Mestrado em Geografia). Universidade Estadual Paulista, Faculdade de Ciência e Tecnologia. Presidente Prudente, 2008.

SILVA, E. C. N. Formação de depósitos tecnogênicos nas proximidades do Conjunto Habitacional Jardim Humberto Salvador e Augusto de Paula na cidade de Presidente Prudente-SP. Monografia (Bacharelado em Geografia). Universidade Estadual Paulista, Faculdade de Ciência e Tecnologia. Presidente Prudente, 2009. 